\title{
Teamwork and team training in the ICU: Where do the similarities with aviation end?
}

\author{
Tom W Reader ${ }^{* 1}$ and Brian H Cuthbertson ${ }^{2}$
}

\begin{abstract}
The aviation industry has made significant progress in identifying the skills and behaviors that result in effective teamwork. Its conceptualization of teamwork, development of training programs, and design of assessment tools are highly relevant to the intensive care unit (ICU). Team skills are important for maintaining safety in both domains, as multidisciplinary teams must work effectively under highly complex, stressful, and uncertain conditions. However, there are substantial differences in the nature of work and structure of teams in the ICU in comparison with those in aviation. While intensive care medicine may wish to use the advances made by the aviation industry for conceptualizing team skills and implementing team training programs, interventions must be tailored to the highly specific demands of the ICU.
\end{abstract}

\section{Introduction}

Teamwork in the intensive care unit (ICU) refers to the leadership, decision-making, communication, and coordination behaviors used by multidisciplinary team members to provide patient care [1]. Patient safety research has demonstrated the importance of effective teamwork for ensuring positive patient outcomes in the ICU. Poor communication during rounds and handovers (or handoffs) is frequently cited as a cause of medical error [2-4], and units with high levels of nurse-doctor collaboration have improved patient mortality rates and reduced average patient length of stay [5]. In attempting to understand and improve teamwork in the ICU, researchers cite teamwork models and training techniques used to manage and improve teamwork skills in

\footnotetext{
*Correspondence: t.w.reader@lse.ac.uk

IInstitute of Social Psychology, London School of Economics, Houghton Street, London, UK, WC2A 2AE

Full list of author information is available at the end of the article
}

aviation [1,6]. Like work environments in aviation, the ICU is a complex, high-risk, and stressful setting, and it can potentially gain from adopting and integrating the principles and techniques used to train team skills in aviation [4]. We consider the case for this and reflect upon the similarities and differences that exist between aviation and intensive care.

\section{The aviation teamwork model}

The aviation model of teamwork draws heavily from social and cognitive psychology and is based on an understanding that team behavior can both cause and protect against error. It considers the team-related 'active failures' (for example, failures to communicate the proximity of nearby aircraft) and 'latent failures' (for example, lack of team training, poor ergonomic design, and organizational culture) that influence behavior and error in the cockpit [7]. Psychology concepts relating to communication, shared decision-making, leadership, team cohesion, team mental models (shared knowledge structures for teamwork and taskwork), and team climate are applied to understand performance and error. Through the use of systemized models, these various concepts are bound together to explain how 'team processes' (for example, leadership and communication) predict 'team outputs' (for example, error and team effectiveness). Furthermore, shared knowledge structures and 'team inputs' (for example, group hierarchies and culture) are shown to influence teamwork behaviors, and safety culture is particularly significant [8].

To understand the specific team behaviors important for safety in aviation, human factor specialists have performed cognitive task analyses, error analyses, attitudinal surveys, observational studies, and ergonomic assessments. These data have structured the content of team training packages [9] and have contributed to the identification of teamwork knowledge, skills, and attitudes that underpin effective team performance (Table 1). Training and assessment in aviation focus on improving communication skills, briefing behaviors, selfcritique, leadership skills, workload management, vigilance and stress management, knowledge of team member skills/roles, and attitudes toward teamwork. Teamwork 
Table 1. Team knowledge, skills, and attitude competencies

\begin{tabular}{ll}
\hline Element & Description \\
\hline Knowledge competencies & Knowing a team's goals, objectives, and resources \\
& Knowing the strategies used to cope with task demands for specific situations \\
& Knowing task procedures and how taskwork will be divided \\
& Knowing team roles and expected interaction patterns between team members \\
& Knowing team member competencies, behavioral tendencies, and strengths and weaknesses \\
& Monitoring team members to support their performance \\
& Providing feedback and coaching to team members whose performance is less than optimal \\
& Recognizing and assisting team members when they need help or are unable to perform effectively \\
& Rapidly adapting to changing events \\
& Ensuring receipt and verification of information when communicating with team members \\
& Ability to cooperate and share problem-solving tasks and to resolve conflicts with mutual satisfaction \\
& Leadership in coordinating and motivating team members, assessing performance, allocating and re-allocating tasks, and \\
& planning and organizing work \\
& Contributing to a positive team climate \\
& Belief in team cohesion \\
Preference for being part of the group & Trust and confidence in team members \\
Preference for approaching problems with a team rather than individual approach \\
Belief in the importance of teamwork and team-oriented behaviors
\end{tabular}

This table, adapted from Baker and colleagues [21] and Salas and colleagues [9], is original and has not been reproduced elsewhere.

research in the ICU has shown that the systems and concepts used to understand team performance in aviation are also relevant for patient safety in intensive care medicine $[1,10]$. However, although team training has become increasingly common within the ICU [11], much can be learned from the aviation industry's advances in developing and integrating into practice the systems for measuring team behavior, providing feedback, and developing teamwork skills.

In aviation, team training is mandatory for commercial pilots in Europe and the US. Virtually all large airlines use team training packages. These use a combination of simulation and class-based training to help aircrews (a) prevent errors from occurring, (b) identify and trap errors, and (c) mitigate the consequences of error [12]. The aviation model provides aircrews with ongoing team training (for example, annually) and uses established pedagogic models to evaluate effectiveness. Such programs have a demonstrable impact on the attitudes of participants toward teamwork, teamwork behaviors, and knowledge of human factors [13]. Validation of crew resource management skills is a training requirement throughout the aviation industry, and best practice is determined by regulators [14]. Despite evidence that the importance of team training is widely accepted in health care, it has not been adopted uniformly and the number of teams that regularly participate in training is still small [15].

Key to the success of team training tools in health care is the identification of the domain-specific team skills required for effectively managing routine and emergency scenarios. In aviation, training strategies have focused on improving the skills required by aircrews to maintain effective decision-making under high levels of stress [9].
Techniques include exposing teams to high-stress situations, training pilots to facilitate team discussions before and after stressful team activities, and cross-training aircrew team members to understand the demands and needs of one another's role. Teams are trained in a multidisciplinary environment (for example, pilots and cabin crew) to facilitate an understanding of the challenges associated with different professional roles, to consider how group hierarchies influence behavior, and to develop expectations for behavior during different scenarios [16]. This training helps aviation teams to form shared and positive perceptions on teamwork and stress management. To assess performance, observational systems for rating teamwork behaviors in the cockpit have been developed. These tools assess teamwork through observable behavioral indicators that indicate good or poor aircrew team skills. Assessment and training can occur at either the individual or group level, and structured qualitative feedback is provided to participants.

It is clear that the team training and assessment techniques used in aviation are relevant to the ICU. For example, in the ICU, as in aviation, hierarchical team structures have a negative impact on the attitudes and behaviors of doctors and nurses and, in turn, on patient safety [4,17]. Furthermore, a range of teamwork and leadership behaviors important for team performance and patient safety have been identified $[1,11,18,19]$. In terms of applying this knowledge to formal team training programs, courses such as Advanced Trauma Life Support teach team skills and may provide a model for introducing team training into the teaching curriculum [20]. Training would consist of general principles underlying optimal team performance in the ICU (for example, 
Table 2. Key stages in the design and implementation of a team training program $[14,21]$

\begin{tabular}{ll}
\hline Stage & $\begin{array}{l}\text { An assessment of the team behaviors associated with effective and safe performance in the task domain must be } \\
\text { made along with an evaluation of the gap between actual and optimal performance. From this assessment, a team } \\
\text { training curriculum can be devised. }\end{array}$ \\
2. Developing training objectives & $\begin{array}{l}\text { The objectives of team training should be explicitly stated (for example, to influence attitudes and behavior) in order } \\
\text { for measures to be developed to assess training efficacy. }\end{array}$ \\
3. Selecting training methods & $\begin{array}{l}\text { Common methods include instructional, demonstrative, or practice-based training, and their usage will depend on } \\
\text { the training objectives. The setting used for team training should be considered carefully along with teaching } \\
\text { resources (for example, availability of high-fidelity simulators and training staff). }\end{array}$ \\
4. Designing a training strategy & $\begin{array}{l}\text { The training strategy should be designed to meet the stated training objectives. This might include (a) introducing } \\
\text { participants to teamwork theory, (b) providing them with opportunities to practice and receive feedback on } \\
\text { teamwork skills, and (c) providing recurrent training to reinforce teamwork skills. }\end{array}$ \\
5. Implementing the team training & $\begin{array}{l}\text { The purpose of a team training program should be clearly articulated and communicated to participants and tutors } \\
\text { prior to implementation. Team training should be blended into practitioner training, and managerial staff must } \\
\text { display a commitment to the importance of team training. The quality of the curriculum and teaching should be } \\
\text { constantly monitored, assessed, and adapted where necessary. }\end{array}$
\end{tabular}

This table is original and has not been reproduced elsewhere.

communication openness) and also the behavioral strategies associated with specific practices (for example, resuscitations). Table 2 notes the key stages associated with implementing an organization-wide team training program [14,21].

Key difficulties in developing such a program would likely be related to the resources involved in managing a comprehensive team training program (for example, trainers, simulators, and clinician time to participate), ensuring that programs are consistent across intensive care medicine, avoiding duplication with other team training programs (for example, anesthesia), generating intuitional support for team training, and identifying the key team training requirements for multidisciplinary ICU teams. To develop team training programs for the ICU, it is necessary to consider the extent to which the models used to conceptualize team performance in aviation can be applied in intensive care medicine.

\section{Comparisons between aviation and the intensive care unit}

As discussed above, parallels have been made between teamwork in aviation and intensive care. ICU teams are also reliant upon teams that manage risk, complex technologies, changeable workloads, and uncertainty [22]. Fatigue and stress are known to negatively influence performance in the ICU [23], and non-technical factors such as team communication, situation awareness, and decision making frequently underlie error [4]. However, there are also a number of general critiques that can be made in the comparisons drawn between aviation and health care [24-26]. For example, owing to the catastrophic consequences associated with in-flight safety failures, there are positive perceptions (and a general awareness) of safety culture throughout aviation. This is not necessarily the case in health care [26]. In addition, medical errors often influence only a single patient (and their family) and, except in cases of negligence, the outcomes rarely impact other patients or health-care providers. In aviation, passengers and aircrews share the consequences of risk. Furthermore, aircrews typically manage stable interlinked systems that operate within expected parameters, and emergency events occur when the functioning of these systems is threatened. Conversely, teams in acute medicine frequently encounter emergency situations. They must tolerate high levels of risk and develop an ongoing understanding of the complex interactions between medical treatments and patient physiology.

In regard to differences between aviation and the ICU, a number of further distinctions can be drawn (Table 3). It is notable that comparisons between aviation and acute medicine often focus on the domains of anesthesia and surgery. This reflects similarities in procedures with aviation (for example, pre-operative checks, induction, extubation, post-operative checks, and awakening). However, the organization of work in intensive care medicine limits the extent to which these parallels can made. For example, unlike aviation work environments, ICUs consist of large medical and nursing teams that care for numerous patients simultaneously. Patients usually enter the ICU in an already critical state. Problem solving is key, and teams must diagnose poorly understood patient illnesses, stabilize the condition of patients, and stimulate recovery. Team members have minimal prior knowledge of patient histories, and patient populations are diverse in terms of demographic background, risk factors, and underlying pathology. 
Table 3. Key similarities and differences in the challenges faced by intensive care unit and aviation teams

\begin{tabular}{|c|c|c|}
\hline & Similarities & Differences \\
\hline Environment/taskwork & $\begin{array}{l}\text { Reliance on complex technology } \\
\text { Constant innovation in technology and working practices } \\
\text { Performance depends on cognitive performance of operators } \\
\text { (for example, situation awareness, problem solving, and } \\
\text { decision making) } \\
\text { Ever-present need to manage uncertainty and risk, particularly } \\
\text { during emergency scenarios } \\
\text { Dependency on multidisciplinary expert teams } \\
\text { Use of handovers to transfer information } \\
\text { Need for collaboration with external agents/units }\end{array}$ & $\begin{array}{l}\text { ICU work is more varied in nature, with teams diagnosing diverse } \\
\text { illnesses, applying treatments, and managing emergencies. } \\
\text { ICU teams tend to perform more'hands-on' work than aviation teams. } \\
\text { Patients are experiencing a crisis on admittance to the ICU; diagnosis } \\
\text { is critical and often teams must apply risky and uncertain } \\
\text { treatments. } \\
\text { Emergency scenarios in the ICU are more common than in aviation. } \\
\text { Resources in the ICU frequently are stretched to capacity (for } \\
\text { example, patient numbers). } \\
\text { Patient outcomes in the ICU are variable; a significant proportion of } \\
\text { patients die. } \\
\text { Duration of patient care can be undeterminable, and treatment } \\
\text { continues after discharge. }\end{array}$ \\
\hline Safety and error & $\begin{array}{l}\text { Error threatens the safety and well-being of patients/ } \\
\text { passengers. } \\
\text { Vigilance and monitoring behaviors are critical for avoiding } \\
\text { error. } \\
\text { Factors such as fatigue, stress, and burnout increase the } \\
\text { likelihood that errors will occur. } \\
\text { Non-technical factors such as communication, situation } \\
\text { awareness, and decision making frequently feature as } \\
\text { causes of error. }\end{array}$ & $\begin{array}{l}\text { Errors in aviation can be identified more easily (for example, through } \\
\text { computers and air traffic controllers). } \\
\text { The magnitude of harm caused by errors in the ICU is less than } \\
\text { in aviation, and consequences/causes of error may not be } \\
\text { immediately noticeable. } \\
\text { Aircrews and passengers share the potential consequences of error. } \\
\text { Error reporting is more commonly discussed in aviation, and staff } \\
\text { have more positive perceptions of safety culture. }\end{array}$ \\
\hline Team performance & $\begin{array}{l}\text { Generic skills, knowledge, and attitudes that underpin effective } \\
\text { teamwork in aviation are likely to be similar in the ICU. } \\
\text { Team hierarchies and group norms can negatively influence } \\
\text { the performance of junior team members (for example, } \\
\text { speaking-up behaviors). } \\
\text { Communication behaviours for building shared mental } \\
\text { models for teamwork and taskwork are important in both } \\
\text { aviation and the ICU. } \\
\text { Effective team leadership is a key determinant of team } \\
\text { performance. } \\
\text { Procedures used to maintain safety in aviation (for example, } \\
\text { checklists) have been shown to have a favorable impact on } \\
\text { outcomes in the ICU. } \\
\text { Simulators can be used for team training in both domains. }\end{array}$ & $\begin{array}{l}\text { Team structures in the ICU differ substantially, and senior doctors } \\
\text { manage large groups of multidisciplinary team members. } \\
\text { Teams in the ICU tend to be more hierarchical in nature. } \\
\text { ICU team leaders have greater autonomy over leadership style and } \\
\text { operating procedures, and leaders rotate on a daily or weekly } \\
\text { basis. } \\
\text { Expertise is widely distributed in the ICU, and trainee doctors learn } \\
\text { 'on the job'and often without direct supervision (for example, at } \\
\text { night). } \\
\text { Team decision-making in the ICU can be influenced by a range } \\
\text { of external parties, including patients, families, surgeons, and } \\
\text { pharmacists. } \\
\text { Protocols for communication tasks and handovers have greater } \\
\text { standardization in aviation. } \\
\text { Standardization for many team-related functions may not be possible } \\
\text { or desirable. }\end{array}$ \\
\hline
\end{tabular}

This table is original and has not been reproduced elsewhere. ICU, intensive care unit.

In addition, the flow of work in the ICU differs considerably from that in aviation. For example, within a single ICU, teams will perform a diverse range of handson, problem-solving, and monitoring tasks [27]. In comparison, aircrews typically monitor and adjust a stable system in which outcomes are usually clear (and positive), and team and task skills are essential for avoiding or managing emergency situations. Problems in aircraft technical performance are often raised through automatic warning systems, and periods of activity tend to be discrete (for example, a 12-hour flight). In the ICU, length of patient care is frequently undeterminable, and the duration of stay depends on the likelihood that patients will experience a sudden deterioration, the stage of treatment, and system factors within a hospital (for example, available bed spaces). Patient outcomes are often unclear, and approximately $20 \%$ of UK patients do not survive intensive care. Furthermore, patient care within the hospital system does not cease when a patient is discharged from the ICU, and patients may return. Numerous clinical and nursing staff may provide patient care, and continuity of care is maintained through regular handovers. While these are key to maintaining the quality and safety of care, they can be un-standardized and subject to error [28]. Furthermore, an ICU will typically have several specialists leading the unit, and compared with their counterparts in aviation, each has substantial autonomy in terms of leadership style and preferred operating procedures. This can result in inconsistencies (between specialists) in their expectations for the 
standards and procedures used to manage patient care and in their expectations for teamwork behaviors and attitudes [19].

Despite these differences, intensive care and aviation teams do share similarities. Both settings involve teamcentric, risky, time-pressured work. They are multidisciplinary in nature and exhibit clear differences in the expertise and authority of team members. Furthermore, team performance is influenced by factors such as team leadership and shared cognition $[19,29,30]$, and lessons can be drawn from the psychology literature on error avoidance and performance-enhancing strategies [8]. It is notable that both ICU specialists and pilots believe in the importance of teamwork for safety and reject steep team hierarchies [31]. However, in comparison with pilots, ICU specialists are less likely to report making errors (or to feel comfortable discussing error), and they tend to have overly positive perceptions (compared with junior team members) toward team communication $[17,32]$. Furthermore, although both aviation work environments and the ICU are highly stressful, intensive care specialists are less likely (than pilots) to acknowledge the detrimental impact of factors such as stress and fatigue upon safety and performance [31].

Team structures in the ICU also differ somewhat from those in aviation. Senior intensivists are generally considered 'expert' in the ICU, and the majority of medical staff are in a training role. Trainees perform much of the hands-on clinical work and must learn to coordinate with nursing teams that have their own team structures, hierarchies, and levels of expertise. At an advanced level, trainees must learn to manage the ICU on their own (for example, at night). Although senior intensivists are available to provide support, the thresholds for requesting help can depend on the trainee's disposition to solicit help and on perceptions of the senior intensivists' attitude toward false alarms. A further difference with aviation is the participation of other actors in 'operational' decision-making. For example, patient decision-making in the ICU can be influenced by non-clinical staff (for example, patients and families) and colleagues from other departments (for example, surgery). However, like aviation teams, ICU teams regularly work with colleagues in other departments (for example, surgery, microbiology, and radiology). Cockpit crews must also coordinate with teams in disparate locations (for example, air traffic control towers). Yet in the ICU (and in healthcare in general), the lines and protocols of communication between hospital units are often informal, un-centralized, and fragmented [26].

An additional parallel between the ICU and aviation is the reliance on protocols to ensure safety and quality. In the ICU, a range of technical protocols are used to structure patient care and ensure safety. Aviation teams also use numerous protocols (for example, pre-flight checks), and within the ICU the emulation of aviation-style protocols to improve patient handovers has been shown to have positive outcomes [33]. However, owing to high levels of uncertainty associated with ICU patients, clinical judgment remains key for determining patient treatments and outcomes, and the extent to which it is desirable to extend protocols to aspects of teamwork and decision making is unclear [15]. Finally, the use of simulation in ICU training is increasing, and this will help to facilitate the adoption of the multidisciplinary team training methods used in aviation.

\section{Conclusions}

On the surface, the aviation model does provide a strong initial platform against which to design and implement team training programs for the ICU. The generic teamwork skills that underpin effective performance are similar, and the process of team training should draw on similar methods and techniques. However, it can be seen that there are many differences between aviation and the ICU in the nature of work and team performance (Table 3). It is not sufficient or desirable to simply transfer to the ICU the programs developed for aviation or the operating theatre (where, it can be argued, the cognitive structure of work is quite similar to that of aviation). Rather, team training in the ICU must consider the ebb and flow of work in critical care, and programs must focus on routine and non-routine events, and be reflective of cognitive tasks, team structures, and group norms. The specific team skills and behaviors that underpin team performance must be captured and explicitly stated if we are to develop a relevant and sustainable model of team training and assessment for the ICU.

This article is part of a series on Healthcare Delivery, edited by

Dr Andre Amaral and Dr Gordon Rubenfeld.

\section{Abbreviation}

$\mathrm{ICU}$, intensive care unit.

\section{Competing interests}

The authors declare that they have no competing interests.

\section{Author details}

'Institute of Social Psychology, London School of Economics, Houghton Street, London, UK, WC2A 2AE. 'Department of Critical Care Medicine, Sunnybrook

Health Sciences Centre, 2075 Bayview Avenue, Toronto, ON, Canada M4N 3M5.

Published: 30 November 2011

\section{References}

1. Reader T, Flin R, Mearns K, Cuthbertson B: Developing a team performance framework for the intensive care unit. Crit Care Med 2009, 35:1787-1793.

2. Donchin Y, Gopher D, Olin M, Badihi Y, Biesky M, Sprung C, Pizov R, Cotev S: A look into the nature and causes of human errors in the intensive care unit. Crit Care Med 1995, 23:294-230.

3. Pronovost PJ, Thompson DA, Holzmueller CG, Lubomski LH, Dorman T, 
Dickman F, Fahey M, Steinwachs DM, Engineer L, Sexton JB, Wu AW, Morlock LL: Toward learning from patient safety reporting systems. J Crit Care 2006, 21:305-315.

4. Reader T, Flin R, Lauche K, Cuthbertson B: Non-technical skills in the intensive care unit. Br J Anaesth 2006, 96:551-559.

5. Baggs JG, Schmitt MH, Mushlin Al, Mitchell PH, Eldrege DH, Oakes D: Association between nurse-physician collaboration and patient outcomes in three intensive care units. Crit Care Med 1999, 27:1991-1998.

6. Sevdalis N, Brett S: Improving care by understanding the way we work: human factors and behavioural science in the context of intensive care. Crit Care 2009, 13:139.

7. Reason J: Human error: models and management. BMJ 2000, 320:768-770.

8. Weiner E, Kanki B, Helmreich RL (Eds): Cockpit Resource Management. San Diego, CA: Academic Press; 1993.

9. Salas E, Bowers C, Edens E (Eds): Improving Teamwork in Organizations: Applications of Resource Management Training. Mawah, NJ: Lawrence Erlbaum Associates, Inc.; 2001

10. Valentin A, Bion J: How safe is my intensive care unit? An overview of error causation and prevention. Curr Opin Crit Care 2007, 13:697-702.

11. Thomas EJ, Sexton B, Helmreich RL: Translating teamwork behaviours from aviation to healthcare: development of behavioural markers for neonatal resuscitation. Qual Saf Health Care 2004, 13:57-64.

12. Helmreich RL, Merritt AC, Wilhelm JA: The evolution of crew resource management training in commercial aviation. Int J of Aviat Psychol 1999, 9:19-32.

13. O'Connor P, Campbell J, Newon J, Melton J, Salas E, Wilson K: Crew resource management training effectiveness: a meta-analysis and some critical needs. Int J of Aviat Psychol 2008, 18:353-368.

14. Flin R, O'Connor P, Crichton M: Safety at the Sharp End: A Guide to NonTechnical Skills. Aldershot, UK: Ashgate; 2008.

15. Gaba D, Rogers J: Have we gone too far in translating ideas from aviation to patient safety? BMJ 2011, 342:198-199.

16. Hamman WR: The complexity of team training: what we have learned from aviation and its applications to medicine. Qual Saf Health Care 2004, 13:72-79.

17. Reader T, Flin R, Mearns $K$, Cuthbertson B: Interdisciplinary communication in the intensive care unit. Br J Anaesth 2007, 98:347-352.

18. Walker S, Brett S, McKay A, Lambden C, Vincent C, Sevdalis N: Observational Skill-based Clinical Assessment tool for Resuscitation (OSCAR): development and validation. Resuscitation 2011, 82:835-844.

19. Reader T, Flin R, Cuthbertson B: Team leadership in the Intensive Care Unit The perspective of specialists. Crit Care Med 2011, 39:1683-1691.
20. Carmont M: The Advanced Trauma Life Support course: a history of its development and review of related literature. Postgrad Med J 2005, 81:87-91.

21. Baker D, Salas E, Barach P, Battles JB, King H: The relationship between teamwork and patient safety. In Handbook of Human Factors and Ergonomics in Health Care and Patient Safety. Edited by Carayon P. Mahwah, NJ: Lawrence Erlbaum Associates, Inc:; 2007:259-271.

22. Bion J, Heffner JE: Challenges in the care of the acutely ill. Lancet 2004, 363:970-977

23. Reader T, Cuthbertson B, Decruyenaere J: Burnout in the ICU: potential consequences for staff and patient well-being. Intensive Care Med 2008, 34:4-6.

24. Shaw J, Calder K: Aviation is not the only industry: healthcare could look wider for lessons on patient safety. Qual Saf Health Care 2008, 17:314.

25. Gaba D: Anaesthesiology as a model for patient safety in health care. BMJ 2000, 320:785-788

26. Vincent C: Patient Safety. London: Elsevier; 2006

27. Fackler J, Watts C, McHugh A, Miller T, Crandall B, Pronovost P: Critical care physician cognitive task analysis: an exploratory study. Crit Care 2009, 13:R33.

28. Raduma-Tomàs M, Flin R, Yule S, Williams D: Doctor's handovers in hospitals: a literature review. BMJ Qual Saf 2011, 20:128-133.

29. Jentsch F, Barnett J, Bowers C, Salas E: Who is flying this plane anyway? What mishaps tell us about crew member role assignment and aircrew situation awareness. Hum Factors 1999, 41:1-14.

30. Reader T, Flin R, Mearns K, Cuthbertson B: Team situation awareness and the anticipation of patient progress during ICU rounds. BMJ Qual Saf 2011, Jun 23. [Epub ahead of print]

31. Sexton J, Thomas EJ, Helmreich RL: Error, stress and teamwork in medicine and aviation: cross sectional surveys. BMJ 2000, 320:745-749.

32. Thomas EJ, Sexton J, Helmreich RL: Discrepant attitudes about teamwork among critical care nurses and physicians. Crit Care Med 2003, 31:956-959.

33. Catchpole K, De Leval M, McEwan A, Pigott N, Elliott M, McQuillan A, MacDonald C, Goldman A: Patient handover from surgery to intensive care: using Formula 1 pit-stop and aviation models to improve safety and quality. Paediatr Anaesth 2007, 17:470-478.

\section{doi:10.1186/cc10353}

Cite this article as: Reader TW, Cuthbertson BH: Teamwork and team training in the ICU: Where do the similarities with aviation end? Critical Care 2011, 15:313. 